\title{
The study of rural landscape at the farm scale: changes in traditional signs and structures
}

\author{
Z. Ludwiczak, S. Benni, P. Tassinari \\ University of Bologna, Department of Agricultural Sciences, Bologna, Italy
}

\begin{abstract}
The importance of cultural, historical and identity values of traditional rural landscapes is widely acknowledged in the relevant scientific fields and in legislation. Furthermore, the knowledge of their evolution represents a fundamental basis in order to manage landscape transformations appropriately. The work is part of a broader research aimed at developing and testing a method for the systematic high time and spatial resolution assessment of changes in traditional rural landscape signs. We describe here the main phases of this original quantitative method and a summary of the first results over an Italian case study. A set of parameters allows to provide complementary information about the evolution of the main characters of rural settlements and their components. This proves to be essential to achieve a deep understanding of the traditional physiognomy of places, and to support landscape management and restoration, and the definition of transformation projects.
\end{abstract}

\section{Introduction and aims}

The importance of cultural, historical and identity values of traditional rural landscapes is widely established both in legislation and at the scientific level. The knowledge of their evolution also represents a fundamental basis for the proper management of future changes of rural landscapes. In fact several studies have dealt with the issue of increasing importance on the recognition and preservation of all types of traditional landscape values (Antrop, 1997; 2000; Pedroli, 2000; Nohl, 2001; Van Eetvelde and Antrop, 2005). However, at present appropriate methods and techniques aimed at creating specific cognitive frameworks in support of policies, plans and projects concerning the extra-urban areas are generally lacking (Antrop 1997, Scazzosi 2002,

Correspondence: Patrizia Tassinari, University of Bologna, Department of Agricultural Sciences, viale G. Fanin 48, 40127 Bologna, Italy.

E-mail: patrizia.tassinari@unibo.it

Key words: traditional rural landscapes, change detection, rural settlements.

(C) Copyright Z. Ludwiczak et al., 2013

Licensee PAGEPress, Italy

Journal of Agricultural Engineering 2013; XLIV(s2):e88

doi:10.4081/jae.2013.s2.e88

This article is distributed under the terms of the Creative Commons Attribution Noncommercial License (by-nc 3.0) which permits any noncommercial use, distribution, and reproduction in any medium, provided the original author(s) and source are credited.
Castelnovi 2004, Van Eetvelde e Antrop 2005, Agnoletti 2013, Cullotta e Barbera, 2011).

The authors have carried out several studies about the analysis of landscape changes of rural landscapes and the rural built heritage (Tassinari et al., 2008;2010a, 2011). Meta-design criteria to improve the quality of the rural settlement system have been defined, and methodologies addressed to integrate analyses and interpretative tools have been proposed (Tassinari et al., 2010b; 2013). Moreover the authors have adopted an original approach considering jointly the rural built environment and the farmyards based on postulates of typological consistency with historic farmsteads (Benni et al., 2012). In fact this study is part of a broader research aimed at defining and testing a high time and spatial resolution systematic method for the assessment of changes in traditional rural landscape signs. This work presents the main phases of the quantitative method developed by the authors and its application to a pilot study case. The goal of the study is the definition of a set of parameters suitable to provide a framework of the evolution of the main characters of the rural built environment and its components. The specific goals consist in the characterization of the traditional landscape arrangements, identification of the trends of landscape evolution (direction and intensity), and recognition of the level of preservation of their signs and structures.

\section{Materials and methods}

The research was developed by referring to a sample of study areas located in the area of the Imola plain (Emilia-Romagna region, Italy). In particular we considered a set of 11 farms with total area of about 200 ha, which had belonged to the institution Hospital Santa Maria della Scaletta, founded in the $15^{\text {th }}$ century (Figure 1). The landscape context of the study area has been characterized since ancient times by a strong farming system - whose traditional signs can be ascribed to the Roman centuriation (Sereni, 1961) - having a prevailing scattered settlement system with open farmyard (Gambi, 1977; Gaiani and Zagnoni, 1997; Ortolani, 1953).

The analysis of the changes of the rural landscape signs at the scale of the farm, together with the broad study of the scientific literature, was conducted based on different sources. In particular we analyzed, besides the various statistical and archival materials, the historical cadastral maps (Nelli Cadastre of 1633-36, Guerrini Cadastre of 173941, Gregorian Cadastre of 1817-35), cabreos and historic maps (Visite Fondi Rustici Appartenenti all'Ospedale S. M. della Scaletta, 1820; Inventario della proprietà terriera appartenente all'ente ospedaliero di Imola, 1932-33; Inventari di consegna dell'ente ospedaliero "Ospedale S. M. della Scaletta di Imola”, 1969-71), Italian Military Geographic Institute (IGMI) maps (1892, 1911, 1956), Regional Technical Maps $(1975,1985,1994)$, satellite and aerial orthoimages (IGMI fly of 195455, Emilia-Romagna fly of 1969-71 and 1976-78, Italy 2000 fly of 1999 QuickBird satellite images of 2003, AGEA fly of 2005). The cartographic 
materials, considered as privileged sources for the ad hoc creation of geo-referenced databases, were acquired in high resolution raster format and processed in GIS environment, using standard procedures (ESRI ArcGIS 9.2).

The general architecture of the method is based on the widely shared and reliable principles of landscape structural analysis, which consist in the decomposition of landscape into its elementary components and the subsequent identification of the structure and their relationships. The main steps of the method named Traditional Rural Landscape Analysis (TRuLAn), based on inputs deriving from both the critical analysis of the state of art and tests over study cases, involve parallel investigation with high time and spatial resolution at the scale of the whole farm and the farmstead.

\section{Phase I. Landscape identification and characterization}

The preliminary phase of characterization of the landscape context involves the identification (through the analysis of literature and available cartographic and descriptive sources) of those elements that make up the formal structure i.e. the physiognomy of landscape. At the farmstead scale, in order to fully grasp the meaning and value of the peculiarities of the settlement system under investigation, it is necessary to identify and characterize its shape and predominant typology within the context, paying particular attention to the settlement structure and the main relationships established between the house and the other components of the agricultural-settlement arrangement. This phase also focuses on the farmstead components attributable to the constructed space, to the open space, with their specialized categories (portions of the farmyard with a functional specialization related to agricultural production or processing of agricultural products, distinct among them also for their physiognomic structure), and the boundary elements.

\section{Phase II. Inventory and parameterization}

This phase is divided into two stages conducted in parallel with continuous interactions: the synchronic and diachronic inventory of countryside signs (stage IIA) and the definition and application of analytical and interpretative tools (stage IIB). In the first step, through a systematic inventory in GIS environment, we identified the basic areal units for the parameterization of the land-use categories recognized at the highest spatial resolution allowed by the cartographic sources (also considering the historical ones that are not coded in the most recent institutional land-use databases) and linear natural or anthropic boundary elements, whose presence within a given land-use areal units generates different land parcels. In stage IIB, we defined and applied the parameters for the characterization of presence/absence and number/variety of elements as well as for the quantification of the distinctive geometric characteristics (size, shape, spatial structure, etc.) and the relationships between the different categories.

\section{Phase III. Analysis and interpretation of changes in rural landscape signs}

This phase is aimed at the integrated interpretation of the results obtained from the computation of two sets of parameters determined at the scale of the farm and the farmstead, using all the available cartographic sources, including those that were not directly used for definition and calculation of the parameters, allowing to more accurately detailing the evolutionary processes, complementing and enriching the data obtained from the quantitative analysis and providing the information for the periods not covered by the parametric analysis.

\section{Results}

The main results about the application of the proposed method to the scale of the farmstead, describing the evolution of the main characteristics of rural settlement and its components, are described below.

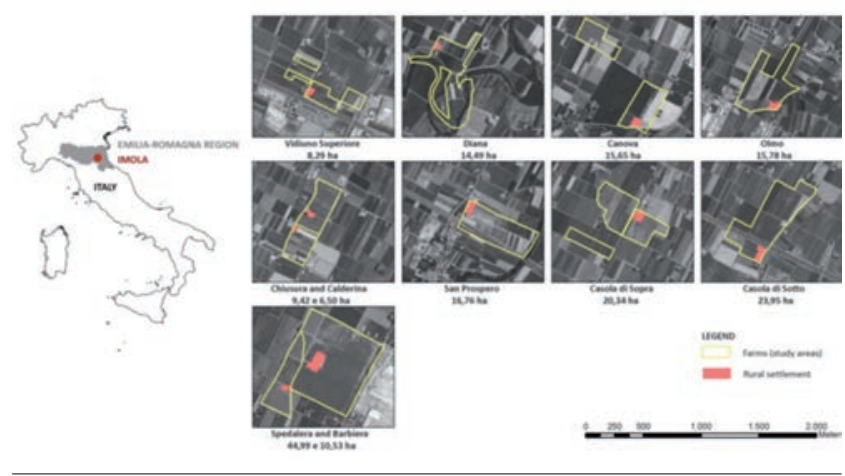

Figure 1. Study areas: geographic location, farm boundaries and farmstead areas (AGEA orthophotos, flight 2005).

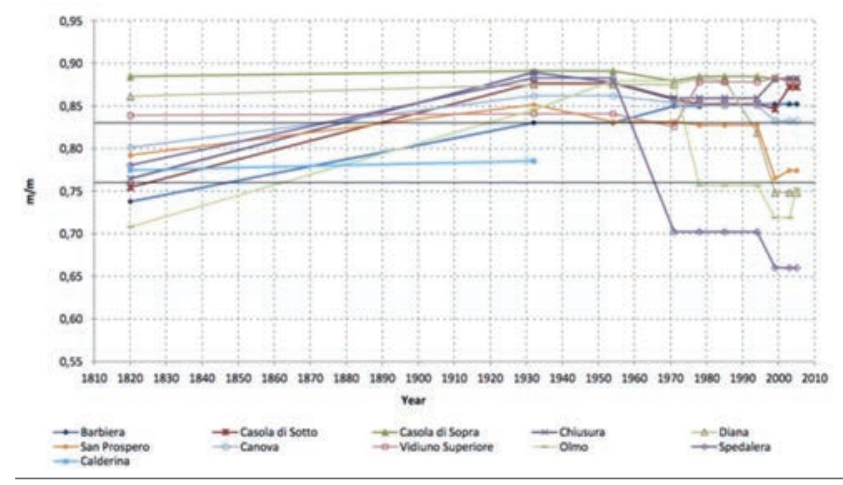

Figure 2. Time changes in CRS (compactness of the rural settlement form) in the analysed farms.

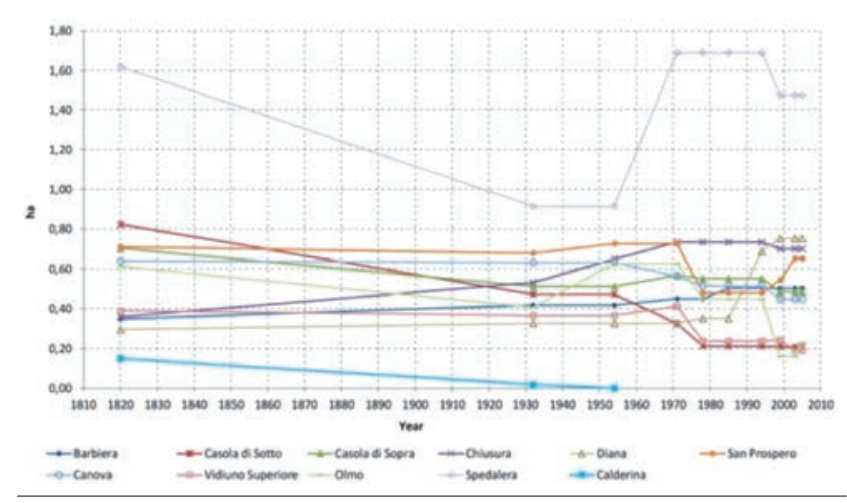

Figure 3. Time changes in ARS (area of the rural settlement) in the analysed farms. 
Table 1. Parameters for the diachronic analysis of the main characters of rural settlements and their elements.

\begin{tabular}{|c|c|}
\hline PARAMETER & DESCRIPTION \\
\hline \multicolumn{2}{|l|}{ The rural settlement } \\
\hline $\begin{array}{l}\text { Area of the rural settlement } \\
\text { [ARS] (ha) }\end{array}$ & $\begin{array}{l}\text { It is the area covered by the farm center, separated from the } \\
\text { surrounding cultivated land by the system of boundary } \\
\text { elements. }\end{array}$ \\
\hline \multirow{3}{*}{$\begin{array}{l}\text { Compactness of the rural } \\
\text { settlement form [CRS] }(\mathrm{m} / \mathrm{m})\end{array}$} & $2 \sqrt{\pi A}$ \\
\hline & $\begin{array}{l}P \text { where A: farm center's area - P: farm center's } \\
\text { perimeter }\end{array}$ \\
\hline & $\begin{array}{l}\text { This index (Turner and Garden 1991) reaches its maximum } \\
\text { value (1) for a circle, while all the other forms show lower } \\
\text { values. The index is equal to } 0,88 \text { for a square, and to } 0,83 \\
\text { and } 0,76 \text { for a rectangle whose sides are in the ratio } 1: 2 \text { and } \\
1: 3 \text { respectively. }\end{array}$ \\
\hline \multicolumn{2}{|l|}{ The built system } \\
\hline Built-up area $[\mathrm{BA}]\left(\mathrm{m}^{2}\right)$ & $\begin{array}{l}\text { All the farm buildings and other build elements are considered. } \\
\text { The diachronic analysis of this parameter agrees to quantify } \\
\text { the development of the built system within the farm. }\end{array}$ \\
\hline $\begin{array}{l}\text { Number of buildings and built } \\
\text { elements [NB] }\end{array}$ & $\begin{array}{l}\text { This value, to be interpreted jointly with the changes in } \mathrm{BA} \text {, } \\
\text { provides information about the characteristics of changes in } \\
\text { the built system, highlighting also the enlargement of existing } \\
\text { building units resulting from the increase of their size or rather } \\
\text { from the juxtaposition of minor building volumes. }\end{array}$ \\
\hline $\begin{array}{l}\text { Number of buildings and built } \\
\text { elements located on the } \\
\text { historical position of buildings } \\
- \text { Share of built-up area } \\
\text { covering the historic position } \\
\text { of buildings [NBH-SBH] (\%) }\end{array}$ & $\begin{array}{l}\text { These parameters quantify the number of buildings and the } \\
\text { share of the total built-up area located on the historical position } \\
\text { as shown in the } 1820 \text { maps, respectively. The diachronic } \\
\text { reading of this parameter allows a better interpretation of the } \\
\text { degree of preservation of the traditional characters related to } \\
\text { the arrangement of buildings and other built elements within } \\
\text { the farm center. }\end{array}$ \\
\hline $\begin{array}{l}\text { Ratio of the built-up area to } \\
\text { the total area of the rural } \\
\text { settlement [RBA] }(\%)\end{array}$ & $\begin{array}{l}\text { Besides quantifying the share of the farm center area covered } \\
\text { by buildings, this parameter provides information about the } \\
\text { open spaces (its complement, varying in inverse proportion). }\end{array}$ \\
\hline \multicolumn{2}{|l|}{ The system of open spaces } \\
\hline $\begin{array}{l}\text { Ratio of the area covered by } \\
\text { specialized open spaces to } \\
\text { the overall farmyard area } \\
\text { [RSO] (\%) }\end{array}$ & $\begin{array}{l}\text { The sum of the areas of all the categories of specialized open } \\
\text { spaces is related to the total area of the farmyard, defined as } \\
\text { the difference between the area of the rural settlement and the } \\
\text { area of the farmstead. }\end{array}$ \\
\hline $\begin{array}{l}\text { Number of specialized open } \\
\text { spaces [NSO] }\end{array}$ & $\begin{array}{l}\text { The number of specialized areas of the farmyard belonging to } \\
\text { the various functional categories. }\end{array}$ \\
\hline $\begin{array}{l}\text { Variety of specialized open } \\
\text { spaces [VSO] }\end{array}$ & $\begin{array}{l}\text { The number of different categories of open spaces which can } \\
\text { be found in the farmyard. }\end{array}$ \\
\hline \multicolumn{2}{|c|}{ The system of boundary elements } \\
\hline $\begin{array}{l}\text { Share of the perimeter of the } \\
\text { rural settlement covered by } \\
\text { physical boundary elements } \\
\text { [SPB] }(\%)\end{array}$ & $\begin{array}{l}\text { It is calculated for each type of vegetation or built boundary } \\
\text { element which defines the boundaries of the farm center. }\end{array}$ \\
\hline $\begin{array}{l}\text { Share of the perimeter of the } \\
\text { rural settlement covered by } \\
\text { vertical boundary elements } \\
\text { [SPVB] (\%) }\end{array}$ & $\begin{array}{l}\text { It is calculated focusing on the overall length of the vegetation } \\
\text { and built elements with a significant vertical development. }\end{array}$ \\
\hline
\end{tabular}

\section{Phase I. Physiognomic analysis}

The analysis of literature and historical documents performed on the sample of the study areas led to the determination of the fundamental components and main characteristics of form and composition of the settlement system investigated, focusing especially on the traditional arrangements. The essential elements of the organization of the rural settlement with open farmyard are attributable to:

its localization (the farmyards may arise along carriage roads or in the midst of cultivated land);

the built environment consisting of all the farm buildings and other built elements variables within the farmstead;

the open spaces of the farmyard, which may include the traditional categories: "macero" (an artificial pond for steeping hemp); "vivajo" or "spinaja" (a plant nursery usually surrounded by hedges); "brolo" or "orto" (orchard or vegetable garden usually surrounded by hedges); "vitaja" (an area for the cultivation of grape); "aia" (threshing floor in clay or bricks);

the system that defines the farmyard boundaries consisting in vegetation elements (such as hedges, rows of trees with or without grapevine) and manufactured (such as public and rural roads, ditches, walls and other fences).

\section{Phase II. Inventory and parameterization}

In Table 1 the main spatial parameters (phase IIB) are presented, first those referring to the whole rural settlement, and subsequently those relative to its components (built space, open space, boundary elements).
Table 2. Synthetic characterization of the boundary systems of the analysed farms.

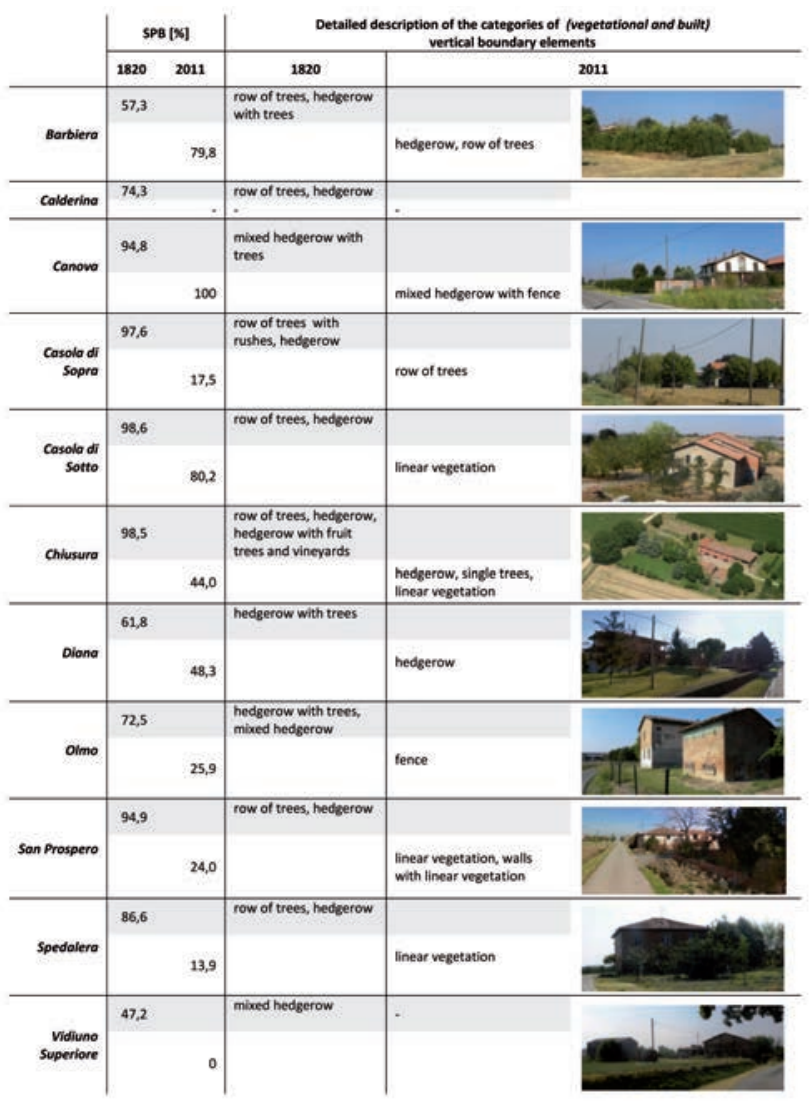

\section{Phase III. Analysis and interpretation of changes in rural landscape signs}

To enable an integrated interpretation of the multidimensional nature of the space-time diversification of physiognomic characters (parameters), the results have been analyzed together with the support of complementary interpretations of different forms of representation. Each parameter has been interpreted by tracing its changes for all the rural settlements, allowing a synthetic study of the trend of each traditional character in a spatial perspective. The temporal variations of all the parameters for each rural settlement have been interpreted together, providing an overview of the respective physiognomic evolution. We carried out the analysis of temporal changes in the coefficient of variation of each parameter, allowing a diachronic reading of the degree of homogeneity/diversity of different physiognomic characters of the rural settlements investigated. The approaches described above call for further integration through a multi-perspective interpretation able to consider the temporal evolution of all the parameters for all rural settlements. To this end, the joint analysis of the groups of parameters, of which the main results are reported in below, proved very useful.

The rural settlement and the built system

In 1820 rural settlements were characterized by high diversification with regard to their size, shape and built area. From 1820-1932 a trend was detected toward uniformity in the character of shape and size (Figures 2 and 3): the size of smaller farmsteads increased and that of larger ones decreased, the traditional long and narrow shape became more compact and the parameters BA and NB did not vary significantly. 
However, putting the relationship these results with RBA and the SBH, we found that the buildings have undergone (partly) demolitions and reconstructions.

In the period 1932-1954 almost all settlements kept their size and shape, whereas in all cases BA began to increase, despite the fact that the total NB usually did not change. The decrease in NBH showed that this increase cannot be attributed only to the widening of existing buildings. Subsequently, in the period 1954-1971, BA kept on growing, while the total ARS remained almost constant, except in some cases where significant increases or vice versa reductions were detected due to external forces (e.g. the transfer of part of the farm for the construction of road infrastructure). In 1971-1978 ARS did not vary, however, the growth of BA was detected. From 1978 to 1994, the values were in line with the previous period. On the contrary, in 1994-1999 several changes were observed that do not allow to identify common trends. Until 2005 (the final time step) no substantial change was detected (Figure 3).

Traditional arrangements of the specialized open spaces

The evolution of farmyard size since 1820 , when a clear diversification was detected (with values between 0.15 and $0.70 \mathrm{ha}$ ), showed an homogeneous trend until 1932, with an increase of minimal areas until 1971, and then a decrease until 1994. In 1971-1978 there was a more significant reduction of size with an overall decrease of ARS and an increase in BA. Until 1994 there were no significant changes and higher variations (both increase and decrease) can be identified in 19942005.

As for the study of changes of specialized open spaces, there was a lack of detailed information in the technical topographical maps and aerial and satellite images, which made unfeasible a diachronic and systematic study of variations in such areas. The integrated analyses of the Gregorian cadastre and cabreos, however, allowed us to return a detailed picture of their traditional arrangement. At present, as shown by surveys, in certain farmyard we observed the presence of specialized open spaces, but they show drastically reduced and the traditional ones are in almost all cases disappeared. At the same time, in relation to the new functions of rural settlements, new categories of such spaces were detected such as ornamental gardens and parking areas.

System of elements which defines the boundaries of the farmyard

For the diachronic analysis of the elements which defines the boundaries of the farmyard, we applied the same considerations about the use and usefulness of the cartographic sources considered for the specialized open spaces. In particular, the structure of the traditional boundaries of the farmyard was reconstructed by means of a thorough reading of the documents of 1820 and compared with the current one (Table 2), through on-site surveys which allowed us to assess their degree of conservation. The surveys carried out showed that traditional vertical boundary elements (mainly vegetation), except in a few cases, occupied between 72 and $100 \%$ of the perimeter of the farmyard. To date, in most cases, vegetation boundary elements have been reduced (they have been preserved mainly along public and rural roads or along farmyards sides adjacent to buildings) or completely disappeared. In the cases in which the vegetation typologies have been preserved, it was noted that over time they have changed their appearance (e.g. following the regular pruning and use of non-native species), often deeply changing the relationships between the perception of the farmstead and its surroundings. Moreover new categories of these elements, e.g. fences, have appeared, partly replacing those missing.

\section{Conclusions}

The TRuLAN method was conceived as a tool of general validity and has been applied and validated on a specific area (Imola plain area). On the one hand, this method is applicable in landscape contexts characterized by agricultural systems and rural and natural conditions which are widely present in the European reality as it is recognized by the scientific literature (Antrop, 2005; Claval, 2005; Skaloš et al., 2011). On the other hand, the structure of the proposed method is applicable in contexts where different types and shapes of rural settlements prevail or the natural and semi-natural elements have greater relevance. However the application of the specific phases requires a calibration of the method, using appropriate checks, integrations and adaptations both of the elements and signs synchronically and diachronically inventoried, and the parameters for their quantitative analysis, whose definition is an essential part of the method.

The high spatial and temporal resolution of the analyses allows to identify and quantify objectively the most minute modalities and trends of changes in rural settlements. The analytical and interpretative tools, aimed at assessing the importance of the diversification of characters in contexts with various sizes and their stay in the short, medium or long term, allow to identify areas with similar characteristics, according to the morphological traits or the physiognomic aspects of certain portions of the territory. This specific landscape characterization is applicable to the field of landscape planning and land-use planning, and in particular in the determination of objective cognitive frameworks as the basis for guidelines and policies at national and regional level, as well as for more specific actions on a local scale, aimed at the preservation, conservation, redevelopment and revitalization of rural areas.

\section{References}

Antrop M. 1997. The concept of traditional landscapes as a base for landscape evolution planning. The example of Flanders Region. Landscape Urban Plan. 38:105-117.

Antrop M. 2000. Background concepts for integrated landscape analysis. Agric., Ecosystems Environ. 77:17-78.

Antrop M. 2005. Why landscapes of the past are important for the future? Landscape Urban Plan.70:21-34.

Agnoletti M. (ed.) 2013. Italian Historical Rural Landscapes. Cultural Values for the Environment end Rural Development. Springer.

Benni S., Torreggiani D., Carfagna E., Pollicino G., Dall'Ara E., Tassinari P. 2012. A methodology for the analysis of dimensional features of traditional rural buildings to implement the FarmBuiLD model. Trans. ASABE, 55(1):241-248.

Castelnovi P. 2004. Il senso del paesaggio e la convenzione europea. In Sargolini M. (ed.) Paesaggio, territorio del dialogo, 59-70. Rome: Kappa.

Claval P. 2005. Reading the rural landscape. Landscape and Urban Planning, 70, 9-19.

Cullotta S. \& Barbera G. 2011. Mapping traditional cultural landscapes in the Mediterranean area using a combined multidisciplinary approach: Method and application to Mount Etna (Sicily; Italy). In Atti di $13^{\circ}$ Conferenza Nazionale ASITA, Bari 1-4 December, 859864.

Gaiani M. \& Zagnoni S. 1997. Iconografia dell'insediamento rurale tra XVI e XIX secolo. In Zaffagni M. (ed.) La casa della Grande Pianura, 169-233. Florence: Alinea.

Gambi L. 1977. Cultura popolare nell'Emilia-Romagna. La casa dei contadini. Milan: Amilicare Pizzi.

Nohl W. 2001. Sustainable landscape use and aesthetic perception preliminary reflections on the future landscape aesthetics. Landscape Urban Plan.: 54:223-237.

Ortolani M.1953. La casa rurale nella pianura emiliana. Firenze - 
Empoli: Poligrafo toscano.

Pedroli B. 2000. Landscape - our Home. Lebensraum Landschaft, Essays on the Cultural of the European Landscape as a Task. Stuttgart: Indiago.

Skaloš J., Weber M., Lipský Z., Trapàkovà I., Šantr kovà M., Uhli ovà L. \& Kukla P. 2011. Using old military survey maps and ortophotograph maps to analyse long-term land cover changes - case study (Czech Republic). Applied Geogr. 31:426-438.

Scazzosi L. 2002. Valutare I paesaggi. In Clementi A. (ed.) Revisioni di paesaggio: studi metodologici per l'applicazione della Convenzione europea del paesaggio. Roma: Meltemi, 217-241.

Sereni E. 1961. Storia del paesaggio agrario italiano. Bari: Laterizia.

Tassinari P., Carfagna E., Benni S., Torreggiani D. 2008. Wide-area spatial analysis: A first methodological contribution for the study of changes in the rural built environment. Biosystems Eng. 100(3):435-447.

Tassinari P., Carfagna E., Torreggiani D., Benni S., Zagoraiou M. 2010a. The study of changes in the rural built environment: Focus on cal- ibration and improvement of an areal sampling approach. Biosystems Eng. 105(4):486-494.

Tassinari P., Torreggiani D., Benni S., Dall'Ara E. 2010b. Research model for farm building design: General structure and physiognomic characterization phase. Agric Eng Int: CIGR J. 12(1):47-54.

Tassinari P., Torreggiani D., Benni S., Dall'Ara E., Pollicino G. 2011. The FarmBuiLD model (farm building landscape design): First definition of parametric tools. J. Cultural Heritage 12(4):485-493.

Tassinari P., Torreggiani D., Benni S. 2013. Dealing with agriculture, environment and landscape in spatial planning: A discussion about the Italian case study. Land Use Policy, 30(1):739-747.

Turner M. G. \& Gardner H. 1991. Quantitative methods in landscape ecology: the analysis and interpretation of landscape heterogeneity. New York: Springer-Verlag.

Van Eetvelde V. \& Antrop M. 2005. The significance of landscape relic zones in relation to soil conditions, settlement pattern and territories in Flanders. Landscape Urban Plan. 70:127-141. 